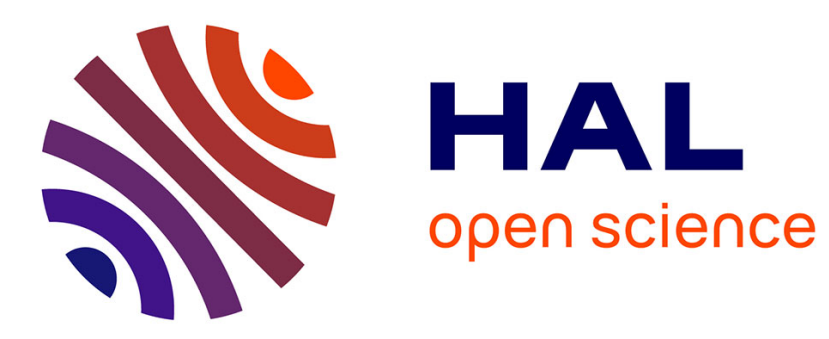

\title{
Modeling the atmospheric dust cycle: 1-design of a soil-derived dust emission scheme
}

\author{
Beatrice Marticorena, Gilles Bergametti
}

\section{To cite this version:}

Beatrice Marticorena, Gilles Bergametti. Modeling the atmospheric dust cycle: 1-design of a soilderived dust emission scheme. Journal of Geophysical Research: Atmospheres, 1995. hal-02324491

\section{HAL Id: hal-02324491 \\ https://hal.science/hal-02324491}

Submitted on 21 Oct 2019

HAL is a multi-disciplinary open access archive for the deposit and dissemination of scientific research documents, whether they are published or not. The documents may come from teaching and research institutions in France or abroad, or from public or private research centers.
L'archive ouverte pluridisciplinaire HAL, est destinée au dépôt et à la diffusion de documents scientifiques de niveau recherche, publiés ou non, émanant des établissements d'enseignement et de recherche français ou étrangers, des laboratoires publics ou privés. 


\title{
Modeling the atmospheric dust cycle: 1. Design of a soil-derived dust emission scheme
}

\author{
B. Marticorena and G. Bergametti \\ Laboratoire Interuniversitaire des Systèmes Atmosphériques, Créteil, France
}

\begin{abstract}
A soil-derived dust emission scheme has been designed to provide an explicit representation of the desert dust sources for the atmospheric transport models dealing with the simulation of the desert dust cycle. Two major factors characterizing the erodible surface are considered: (1) the size distribution of the erodible loose particles of the soil which controls the erosion threshold and the emission strength and (2) the surface roughness which imposes the efficient wind friction velocity acting on the erodible surface. These two parameters are included in a formulation of the threshold wind friction velocity by adapting a size-dependent parameterization proposed by Iversen and White (1982) and by applying to the rough erodible surfaces a drag partition scheme derived from Arya (1975). This parameterization of the threshold friction velocity has been included in an horizontal flux equation proposed by White (1979). This allows to attribute a specific production rate to each soil size range for each type of surface. The dust flux $F$ is then considered as a fraction of the total horizontal flux $G$, the value of the ratio $F / G$ being imposed, at this time, by the soil clay content. In summary, the computed mass fluxes depend on the soil size distribution, the roughness lengths, and the wind friction velocity. The different steps of this scheme have been independently validated by comparison with relevant experimental data. Globally, the agreement is satisfying, so that the dust fluxes could be retrieved with less uncertainties than those observed in previous simulations of the desert dust cycle.
\end{abstract}

\section{Introduction}

Soil-derived dust represents one of the major components of the natural atmospheric aerosol. These mineral aerosols are mainly produced by the aeolian erosion occurring in arid or semiarid areas and their emission strength is highly sensitive to changes in some climatic parameters such as wind velocity and precipitation. On a decennial timescale, Prospero and Nees [1977] have shown how 10 years of drought in Sahel can affect the desert dust load over the north tropical Atlantic Ocean. On a larger timescale, strong increases of the atmospheric dust content have been observed for the glacial periods [De Angelis et al., 1987]. In particular, it has been proved, from polar ice cores, that the atmospheric concentration of insoluble aluminium was 5 to 10 times higher during the last glacial maximum (LGM) than the present one [Thompson, 1977; Petit et al., 1981]. Analyses of Antarctic dust also allow to deduce specific geographic origins for dust. For example, strontium and

Copyright 1995 by the American Geophysical Union.

Paper number 95JD00690.

0148-0227/95/95JD-00690\$05.00 neodymium isotopic ratios of dust trapped in the Dome-C ice core have assigned a Patagonian origin for the LGM dust [Grousset et al., 1992]. This indicates that desert dust can be used as a paleoclimatic tracer to test simulations of past climates and atmospheric circulation, and further to understand the mechanisms of the climatic changes.

Simulations of the desert dust cycle would also help in understanding how dust emissions and climatic changes interact. Especially, it could be useful to evaluate how the dust production could be influenced by the climatic changes forecasted for the near future and if the expected increase of mineral aerosols could contribute to a possible cooling due to their optical properties.

Many attempts have been made to simulate the desert dust cycle at a global scale by using general circulation models [Joussaume, 1990, 1993; Genthon, 1992]. However, these simulations generally failed in reproducing the present data or the measurements obtained for the LGM [Gaudichet et al., 1992]. According to the authors, deficiencies in source parameterization account for a large part of the observed discrepancies. Generally, in those simulations the dust production function is only dependent on the extent of the desert regions and on the wind velocity: (1) Dust emissions are always defined as a continuous function of the wind velocity, whereas many experiments clearly indicate that the dust mobilization 
occurs only for wind velocities higher than a threshold value and that the production is not linearly dependent on the wind velocity [Bagnold, 1941] and (2) the source regions are defined either like the present arid zones or according to the simulated mean aridity, but all the desert zones are considered as emission areas of equal erodibility. It has been experimentally shown that the erodibility depends strongly on the soil texture and on the ground surface characteristics (vegetation cover, rocks, and pebbles) [Gillette, 1979]. The lack of such soil features dependence in the source parameterization may explain shortcomings in the simulations concerning the underestimation or overestimation of dust production for specific regions.

The dust emission model proposed here tries to account for the variability in source erodibility by a parameterization of the erosion threshold based on the size distribution of the erodible soils and the roughness length of the surface. This parameterization of the soil and surface properties is then included in dust flux expressions that have been experimentally tested.

A companion paper will deal with a large-scale (Saharan Desert) simulation performed with this production model and the methods developed to provide the required parameters.

\section{Description of the Physical Scheme}

\subsection{Physical Approach}

Dust production in arid zones is connected to aeolian transport of soil grains. From a physical point of view, the particles motion initiated by wind is controlled by the forces acting on them. For a particle at rest, these forces are the weight, the interparticle cohesion forces, and the wind shear stress on the surface. The first ones are size dependent; the last one depends on the transfer of the wind energy to the erodible surface which is controlled by the presence of roughness elements on the surface. All together determine the minimum threshold friction velocity, $U_{t}^{*}$ required to initiate particle motion (the friction velocity being defined as the square root of the ratio of surface stress to air density).

Once the particle is in motion, its path depends on the budget between its weight acting downward and the opposite aerodynamic drag. The vertical extent of these trajectories defines three major types of grain motion, generally classified in relation with the particle size [Bagnold, 1941].

The finest particles $(<60 \mu \mathrm{m})$, or desert dust, are small enough to be transported upward by turbulent eddies, sometimes very far from the sources. This movement is called "suspension".

The soil grains in the range of 60 to $2000 \mu \mathrm{m}$ are able to be lifted from the surface at a height of some tenths of centimeters; but as the drag is not sufficient to exceed the weight, they are carried downwind back to the surface. Such trajectories define a motion called "saltation". The maximum height of the saltation layer, limited by the vertical extent of these paths, is of the order of $1 \mathrm{~m}$. It must be underlined that these saltating grains, alternating contact with the surface and the air, remove momentum from the air and thus produce a sort of resistance to the wind.

At least, the particles too large or too heavy to be lifted from the surface $(>2000 \mu \mathrm{m})$ roll and creep along the surface in a motion called "creeping". The total amount of material in movement is located near the surface in the saltation layer. It is represented by the vertically integrated horizontal flux G. The dependence of the horizontal flux with the wind friction velocity has been largely investigated, mainly by wind-tunnel experimentation, leading to various predictive flux equations (a review of these flux expressions was given by Greeley and Iversen [1985]). These expressions generally involve a power law of the wind friction velocity and include a threshold wind friction velocity.

$$
\mathrm{G}=\mathrm{f}\left(\mathrm{U}^{* \mathrm{X}}, \mathrm{U}_{\mathrm{t}}^{*}\right) \mathrm{g} \mathrm{cm}^{-1} \mathrm{~s}^{-1}
$$

The fine suspended particles constitute the dust flux, which is referred as the vertical flux F. Since dust production experiments can hardly be performed in the wind tunnel the physical processes of dust emission are not yet well identified and described. Thus the vertical flux is generally estimated from the horizontal flux and so involves equations having roughly the same form.

In such expressions the term characterizing the source specificity is the threshold friction velocity. To estimate total dust production in the United States, Gillette and Passi [1988] have developed a model based on Owen's (unpublished manuscript, 1987) flux formulation and on an extrapolation of threshold friction velocity measurements assigned to nine soil-type families. Even if such an approach could be valuable when a large number of reliable measurements of threshold friction velocities is available, it cannot be used as an interpretative tool of the mechanisms of dust production and of their evolution. From this point of view, an explicit parameterization of the threshold friction velocity $U_{t}^{*}$ in relation with the surface characteristics of the sources is needed.

It has been experimentally shown that both the eroded mass flux and the size distribution of the flux depend on the size distribution of the initial particle bed [Sörensen, 1985; Li and Marz, 1994]. Moreover Nickling [1988] indicates that the threshold friction velocity of a natural sediment cannot be represented by a single value. Indeed erosion thresholds observed for both natural and wind tunnel experiments on rough surfaces are significantly higher than those observed on smooth surfaces [Musick and Gillette, 1990; Gillette et al., 1982]. So we have 
developed a parameterization of $U_{t}^{*}$ in relation to the size of the erodible particles and the effect of the roughness elements, which controls the wind shear stress on the surface.

\subsection{Parameterization of the Threshold Friction Velocity}

The size dependence of the threshold wind friction velocity has been largely investigated. The available predictive formulations are generally used to affect the threshold value corresponding to the median diameter of the soil grains. Our intention is to associate to each soil grain the appropriate threshold wind friction velocity. Semiempirical equations proposed by Iversen and White [1982] are modified to obtain a direct relationship between the particle diameter and the threshold wind friction velocity.

2.2.1. Threshold friction velocity versus soil particle size. A theoretical formulation of the threshold friction velocity $\mathrm{U}_{\mathrm{t}}^{*}$ can be established by considering the equilibrium of the forces acting on a spherical loose particle at rest on a similar particle bed under an air flow stream. At the threshold of aeolian erosion the aerodynamic forces due to the fluid equal the particle weight and the interparticle cohesion forces.

Based on a similar analysis but ignoring the cohesion forces, Bagnold [1941] gave the following formulation for $\mathrm{u}_{\mathrm{t}}^{*}$ :

$$
\mathrm{U}_{\mathrm{t}}^{*}=\mathrm{A}\left(\frac{\rho_{\mathrm{p}} \mathrm{g} \mathrm{D}_{\mathrm{p}}}{\rho_{\mathrm{a}}}\right)^{0.5}
$$

where $\mathrm{g}$ is gravitational acceleration; $\rho_{\mathrm{p}}$ is particle density; $D_{p}$ is particle diameter and $\rho_{a}$ is air density. $A$ is called the dimensionless threshold parameter and is expected to depend on the friction Reynolds number $B$ which is defined at the erosion threshold as follows:

$$
\mathrm{B}=\frac{\mathrm{U}_{\mathrm{t}}^{*} \mathrm{D}_{\mathrm{p}}}{\mathrm{v}}
$$

with $v$ the kinematic viscosity of the air.

Experimental data from Bagnold [1941] and Chepil [1945] confirmed this size dependence but also revealed an increase of the threshold friction velocity values for the smallest particles. This determines an optimum particle size $(\sim 60 \mu \mathrm{m})$ for which the threshold friction velocity is minimum. Iversen et al. [1976] considered that interparticle cohesion forces could be responsible for this unexpected behavior of the finest particles. Based on a large set of measured threshold friction velocities obtained in wind tunnels and involving various particle densities (0.21 to $11.35 \mathrm{~g} \mathrm{~cm}^{-3}$ ) and diameters (12 to $1290 \mu \mathrm{m}$ ),
Iversen and White [1982] proposed new formulations to predict the saltation threshold friction velocity, including the effect of the interparticle cohesion forces. Two numerical expressions for A were established by fitting semiempirical relations on experimental data, each of them corresponding to a different range of the Reynolds number for $0.03<\mathrm{B}<10$,

$$
\mathrm{U}_{t}^{*}\left(\mathrm{D}_{\mathrm{p}}\right)=\frac{0.129 \mathrm{~K}}{\left(1.928 \mathrm{~B}^{0.092}-1\right)^{0.5}}
$$

for $B>10$,

$$
\left.\mathrm{U}_{\mathrm{t}}^{*}\left(\mathrm{D}_{\mathrm{p}}\right)=0.12 \mathrm{~K}\left[\begin{array}{lll}
1-0.0858 & \exp (-0.0617 & (\mathrm{B}-10)
\end{array}\right)\right]
$$

with $K=\left(\frac{\rho_{p} g D_{p}}{\rho_{a}}\right)^{0.5}\left(1+\frac{0.006}{\rho_{p} g D_{p}^{2.5}}\right)^{0.5}$

(notewell that the unit of the factor 0.006 in both equations is $\mathrm{g} \mathrm{cm}^{0.5} \mathrm{~s}^{-2}$; all the others are dimensionless).

The difficulty in using the above equations results from $B$ being dependent both on $D_{p}$ and $U_{t}^{*}$, implying an iterative calculation to determine $U_{t}^{*}$ versus $D_{p}$. We determined numerically couples of values $\left(U_{t}^{*}, D_{p}\right)$ and the corresponding values for $\mathrm{B}$, in a situation we are interested in (terrestrial conditions $\rho_{\mathrm{a}}=0.00123 \mathrm{~g} \mathrm{~cm}^{-3} ; \rho_{\mathrm{p}}=2.65 \mathrm{~g}$ $\left.\mathrm{cm}^{-3}\right)$. An approximate expression for $\mathrm{U}_{t}^{*}$ versus $\mathrm{D}_{\mathrm{p}}$ was then fitted by matching the Reynolds number in the following form:

$$
B=a D_{p}^{x}+b
$$

with $a=1331, b=0.38$, and $x=1.56$. To respect the dimensionless Reynolds number, a has a unit of $\mathrm{cm}^{-\mathrm{x}}$.

By including this analytical solution of the Reynolds number in the Iversen and White expressions, one can compute $U_{t}^{*}$ as a function only of the particle diameter, for (2) air and particle densities indicated previously. For $0.03<\mathrm{B}<10$,

$$
\mathrm{U}_{\mathrm{t}}^{*}\left(\mathrm{D}_{\mathrm{p}}\right)=\frac{0.129 \mathrm{~K}}{\left(1.928\left(a \mathrm{D}_{\mathrm{p}}^{\mathrm{X}}+\mathrm{b}\right)^{0.092}-1\right)^{0.5}}
$$

for $B>10$,

$$
U_{t}^{*}\left(D_{p}\right)=0.129 \mathrm{~K}\left[1-0.0858 \exp \left(-0.0617\left(\left(a D_{p}^{x}+b\right)-10\right)\right)\right](7)
$$

For the range 1 to $1000 \mu \mathrm{m}$ the errors on the threshold values calculated by using the fitted expression of $B$ in 
equations (6) and (7) never exceed $3 \%$ compared to the initial values. The largest discrepancies are observed for particle diameters smaller than $10 \mu \mathrm{m}$ (Figure 1).

Finally, these semiempirical expressions are easy to use and provide a very satisfying estimation of the threshold friction velocity as a function of the particle diameter for terrestrial conditions and in a situation where the wind energy transfer is assumed to be complete since no roughness elements were present during the wind-tunnel measurements.

2.2.2. Parameterization of the drag partition. A second factor that strongly affects the erosion threshold in natural situations is the presence of nonerodible elements. They affect the erosion threshold by two ways. On one hand, the roughness elements cover part of the surface and thus protect it from the aeolian erosion; on the other hand, they consume part of the wind momentum that will not be available to initiate particle motion. This leads to a global decrease of the wind shear stress acting on the erodible surface and thus of the erosion efficiency. So, a physical scheme of the drag partition between the roughness elements and the erodible surface is necessary to parameterize the threshold friction velocity in "rough" situations, which are the most frequent in desert areas.

Based on an approach proposed by Schlichting [1936], Marshall [1971] expressed the overall shear stress caused by wind passing over a roughened surface as being partitioned between stress on the roughness elements and stress on the noncovered surface:

$$
\tau=\rho_{\mathrm{a}} \mathrm{U}^{* 2}=\frac{\mathrm{W}_{\mathrm{R}}}{\mathrm{S}}+\frac{\mathrm{S}^{\prime}}{\mathrm{S}} \tau_{\mathrm{S}}
$$

where $\tau$ corresponds to the overall shear stress, $S$ is the total surface; $S^{\prime}$ refers to the uncovered surface; $W_{R}$ is the force exerted on the roughness elements and $\tau_{S}$ is the shear stress acting on the uncovered surface.

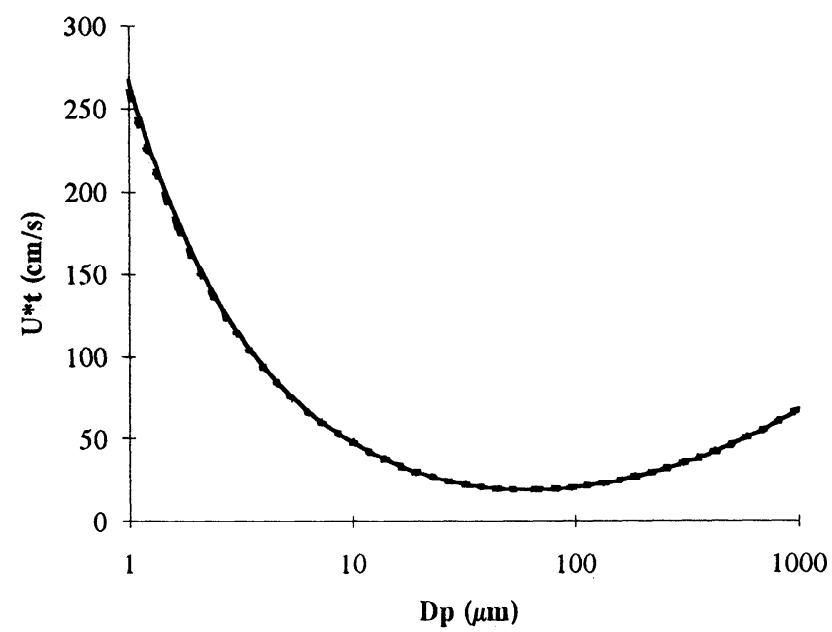

Figure 1. Relationship of threshold friction velocity $\left(\mathrm{U}_{\mathfrak{t}}^{*}\right)$ to particle diameter $\left(D_{\mathrm{p}}\right)$; dotted curve: from Iversen and White expressions (4) and (5); solid curve: from equations (6) and (7).
The force exerted on the roughness elements and thus their momentum absorption is primarily controlled by their frontal surface. That is why the description of the drag partition generally involves a roughness density (also called lateral cover), which is defined by

$$
\lambda=\frac{\mathrm{nbh}}{\mathrm{S}}
$$

where $\mathrm{n}$ is the number of roughness elements; $\mathrm{b}$ is the mean breadth of the roughness elements and $h$ is the mean height of the roughness elements.

To investigate the relation between the drag partition and $\lambda$, Marshall [1971] has performed wind-tunnel measurements of the overall shear stress and of the forces acting on the roughness elements for a large range of roughness densities ( $\lambda$ ranging from $\sim 0.0002$ to 0.2 ). Roughly, $\tau_{\mathrm{s}}$ decreases as the roughness density increases and becomes negligible for a value of $\lambda=0.03$. This provides an estimation of the critical value of the roughness density for which the decrease of the wind shear stress on the uncovered surface is such that it inhibits erosion.

The consequences of the drag partition on erosion is that erodible surfaces covered with roughness elements have higher apparent threshold friction velocities than surfaces with less roughness elements. For erosion to occur, the shear stress component acting on the erodible surface must at least equal $\left(\rho_{\mathrm{a}} \mathrm{U}_{\mathrm{ts}}^{* 2}\right)$ which is the shear stress corresponding to the threshold wind friction velocity in a "smooth" situation. This explains why the threshold friction velocities $U_{\mathfrak{t}}^{*}$ measured in situations with roughness elements are apparently higher than in smooth situations. The ratio of smooth to rough threshold friction velocities is generally called the critical friction velocity ratio (CFRV), as defined by Gillette and Musik [1990]:

$$
\mathrm{CFRV}=\frac{\mathrm{U}_{\mathrm{ts}}^{*}}{\mathrm{U}_{\mathrm{t}}^{*}}
$$

To determine predictive expressions for practical applications, Raupach [1992] proposed an analytical treatment of the drag partition on a rough surface based on a dimensional analysis and physical hypothesis. The proposed equation gives the ratio of the overall shear stress to the shear stress on the uncovered surface as a function of $\lambda$ :

$$
\frac{\tau}{\tau_{S}}=\frac{1}{(1-m \sigma \lambda)} \frac{1}{(1+m \beta \lambda)}
$$

$\sigma$ is the basal to frontal area ratio of the roughness elements; $\beta=C_{R} / C_{S}$, where $C_{R}$ and $C_{S}$ are, respectively, the drag coefficients of an individual roughness element and of the smooth surface.

The predictions based on this equation agree well with Marshall's data and other measurements performed in 
wind tunnel or for natural sites, and thus this formulation can be considered as the best available to retrieve the drag partition on a rough surface.

One of the advantages of the expression, initially proposed by Raupach [1992], was to be predictive and to be free of any adjustable constant; but when applied to real situations, this formulation requires the introduction of an empirical parameter called m. Raupach et al. [1993] indicates that this parameter could reflect the differences between the average substrate surface stress and the maximum stress on the surface at any point. The adjustment of this equation to erosion data has lead to the recommendation of two kinds of values for $\mathrm{m}$ according to the stabilization state of the particle bed; but no objective method to generalize these values are indicated, this coefficient does not refer to any measurable value. Indeed, the practical use of equation (11) as a predictive tool is not evident because of the difficulty in estimating the parameters $m$ and $\beta$. For example, to represent the shear stress partition in sparsely vegetated desert canopies, Wolfe and Nickling [1994] test various combinations of values for $\mathrm{m}$ and $\beta$, the appropriate values being determined a posteriori as those matching the experimental data. The measurements of drag coefficients of isolated roughness elements reported in the literature are scarce, and no relation has been established to extrapolate these values to other kinds of elements. Moreover, the roughness density, defined by the mean frontal area of the roughness elements, may not be representative of the aerodynamic effect of the roughness elements in natural situations, in particular to represent vegetation or for situations where their dimensions and spacing are not regular. In the least, this expression does not seem to be appropriate for large-scale modeling issues.

An alternative specification of the drag, using a more integrative parameter to represent the effect of the roughness elements, is based on the roughness length $z_{0}$. It is the length scale that characterizes the loss of wind momentum attributable to the roughness elements. Such an approach has been developed by Arya [1975] to determine the wind stress on the Arctic pack ice.

Under adiabatic conditions the wind profile in the atmospheric boundary layer (ABL) is logarithmic [Priesley, 1959] and defined, for $Z>>Z_{0}$, as

$$
\mathrm{U}(\mathrm{Z})=\frac{\mathrm{U}^{*}}{\mathrm{k}} \ln \left(\frac{\mathrm{Z}}{\mathrm{Z}_{0}}\right)
$$

where $\mathrm{U}(\mathrm{Z})$ is the wind velocity at the height $\mathrm{Z} ; \mathrm{k}$ is the Von Karman's constant ( 0.4$)$; $\mathrm{U}^{*}$ is the wind friction velocity and $Z_{0}$ is the roughness length.

Arya defines the overall shear stress over the rough surface:

$$
\tau=\rho_{\mathrm{a}} U^{*}
$$

with $\mathrm{U}^{*}$ the overall friction velocity.
Then, for situations where roughness elements are not too closely spaced $(\lambda<0.05)$, he assumed that an internal boundary layer (IBL) grows behind the roughness elements. The development of this IBL is assumed to be similar to the development of the IBL occurring after a sudden change in roughness. This problem has been thoroughly investigated both theoretically and experimentally. When the equilibrium with the new surface has been reached, Arya assumed that the wind profile in the IBL also follows a logarithmic law for $\mathrm{z}<\delta$ :

$$
\mathrm{U}(\mathrm{z})=\frac{\mathrm{US}_{\mathrm{S}}^{*}}{\mathrm{k}} \ln \left(\frac{\mathrm{z}}{\mathrm{z}_{0 \mathrm{~s}}}\right)
$$

$\mathrm{U}_{\mathrm{S}}^{*}$ is the small-scale friction velocity referred to the local shear stress $\tau_{\mathrm{s}}=\rho_{\mathrm{a}} \cdot \mathrm{U}_{\mathrm{s}}^{* 2} ; z_{0 \mathrm{~s}}$ is the local roughness length of the uncovered surface, i.e., the smooth roughness length and $\delta$ is the height of the IBL.

Such a wind profile hypothesis for the IBL is in good agreement with O'Loughlin and Annambhotla's [1969] wind-tunnel observations, and with Arya and Shipman [1981] and Pendergrass and Arya's [1984] field experiments.

At the top of the IBL is a blending zone which represents the wake effect of a single element. Far downstream from the element, this effect becomes very weak and this transition zone is thin enough to be neglected. The height of the IBL $\delta$ can then be defined as the height where the two profiles intersect. Thus when the flow comes to an equilibrium with the surface, the wind velocity at the height $\delta$ satisfies both equations (13) and (14):

$$
\mathrm{U}(\delta)=\frac{\mathrm{U}^{*}}{\mathrm{k}} \ln \left(\frac{\delta}{\mathrm{Z}_{0}}\right)=\frac{\mathrm{U}_{\mathrm{s}}^{*}}{\mathrm{k}} \ln \left(\frac{\delta}{\mathrm{Z}_{0 \mathrm{~s}}}\right)
$$

Thus the ratio of local to total shear stress is defined by

$$
\frac{\tau_{s}}{\tau}=\left(\frac{\mathrm{U}_{\mathrm{s}}^{*}}{\mathrm{U}^{*}}\right)^{2}=\left(\frac{\ln \left(\frac{\delta}{\mathrm{Z}_{0}}\right)}{\ln \left(\frac{\delta}{\mathrm{z}_{0 \mathrm{~s}}}\right)}\right)^{2}
$$

For convenience, an efficient friction velocity ratio $f_{\text {eff }}$ is defined as the ratio of local to total friction velocity:

$$
\mathrm{f}_{\mathrm{eff}}=\frac{\mathrm{U}_{\mathrm{S}}^{*}}{\mathrm{U}^{*}}=1-\left(\frac{\ln \left(\frac{\mathrm{Z}_{0}}{\mathrm{Z}_{0 \mathrm{~s}}}\right)}{\ln \left(\begin{array}{c}
\delta \\
\mathrm{z}_{0 \mathrm{~s}}
\end{array}\right)}\right)
$$

According to Elliott [1958] it is reasonable to assume that the flow does not immediately adjust to the new surface. 
The adjustment takes place gradually, and the height of the IBL $\delta$ increases with distance downwind from the point of discontinuity in roughness, as expressed by

$$
\frac{\delta}{\mathrm{z}_{0 \mathrm{~s}}}=\mathrm{a}\left(\frac{\mathrm{x}}{\mathrm{z}_{0 \mathrm{~s}}}\right)^{\mathrm{p}}
$$

Elliott indicates that $\mathrm{p}$ can be taken constant $\cong 0.8$ over a large range of roughness length and that a should verify the relation

$$
a=0.75-0.03 \ln \left(\frac{Z_{0}}{z_{0 s}}\right)
$$

where $Z_{0}$ is the initial roughness length; $z_{0 s}$ is the smooth roughness length after the change; and $x$ is the distance downstream the point of discontinuity in roughness.

Experimental data obtained by Glaser [1955] over a runway in Louisiana on a hot day confirm expression (17) and a value of 0.8 for $p$; but the ratio $z_{0} / z_{0 s}$ was not measured with sufficient accuracy to validate relation (18). Elliott also mentioned that Glaser's [1955] measurements were performed on a hot clear day so that the temperature gradient was definitely nonadiabatic. Pendergrass and Arya [1984] have experimentally studied in a wind tunnel the development of boundary layers representative of rural and urban environments in neutral conditions. Their results, based on both mean velocity and turbulent measurements, also validate Elliott's formulation but indicate $\mathrm{a} \cong 0.35$ in adiabatic conditions. Since such conditions are coherent with the wind profile hypothesis, this last value will be retained here.

Since $\delta$ is dependent on the distance downstream of the roughness element, $f_{\text {eff }}$ is not constant: the local shear stress increases until an equilibrium value is eventually reached. A rigorous computation of the mean efficient shear stress on the erodible surface should integrate this variation along the distance $d$ between the roughness elements. However, for large-scale applications, the distance between the roughness elements will be variable and will not be precisely determined. Moreover, an integrative computation will be too time consuming. That is why we tried to test if a mean value for $\delta$ can be defined to correctly estimate the efficient ratio over a large range of roughness lengths. Various simulations have been performed, corresponding to roughness elements varying from 2.2 to $20 \mathrm{~cm}$ height, and spacing from a few to hundreds centimeters, corresponding to roughness density from 0.001 to 0.2 . For each simulated situation the mean value of $f_{\text {eff }}$ is rigorously computed, using equations (16) and (17) and compared to the values obtained with a unique value of $X$. The difference between the efficient fractions computed when using $X=10 \mathrm{~cm}$ and the mean efficient fractions are of the order of $20 \%$ for $f_{\text {eff }}$ higher than 0.2 . These results indicated that $f_{\text {eff }}$ is not very sensitive to $X$ but is mainly dependent on the values of the roughness lengths. This has also been pointed out by simulating Marshall's measurements of the efficient ratio. The overall shear stress was measured with a drag plate and deduced independently from the momentum integral method, both methods being in agreement. The shear stress due to the roughness elements was obtained by measuring directly the force on an individual mounting element with a drag balance. The shear stress on the surface is deduced from these measurements. The overall friction velocities are computed from the measured total shear stresses. The experimentation being performed with a constant free stream wind velocity $\left(20.3 \mathrm{~cm} \mathrm{~s}^{-1}\right)$ at the height of $4.6 \mathrm{~cm}$, the values of the roughness lengths are then computed by assuming a logarithmic profile for the wind velocity. The wind profile corresponding to the measurements performed without roughness elements gives the value of the smooth roughness length for which $f_{\text {eff }}=1$. Figure 2 shows that over a large range of roughness lengths the efficient ratios computed with a unique value of $X=10 \mathrm{~cm}$ are in satisfying agreement with Marshall's measurements. This indicated that the efficient ratio is mainly controlled by the values of the two roughness lengths.

Thus the drag partition parameterization is expressed by

$$
\mathrm{f}_{\mathrm{eff}}=\frac{\mathrm{U}_{\mathrm{s}}^{*}}{\mathrm{U}^{*}}=1-\left(\frac{\ln \left(\frac{\mathrm{z}_{0}}{\mathrm{z}_{0 \mathrm{~s}}}\right)}{\ln \left(0.35\left(\frac{10}{\mathrm{z}_{0 \mathrm{~s}}}\right)^{0.8}\right)}\right)
$$

$Z_{0}$ and $z_{0 s}$ having units of centimeters.

The relation observed between the measured efficient ratios and the roughness lengths suggests that $Z_{0}$ could be a relevant parameter to represent the drag partition. The comparison between the computed and the measured

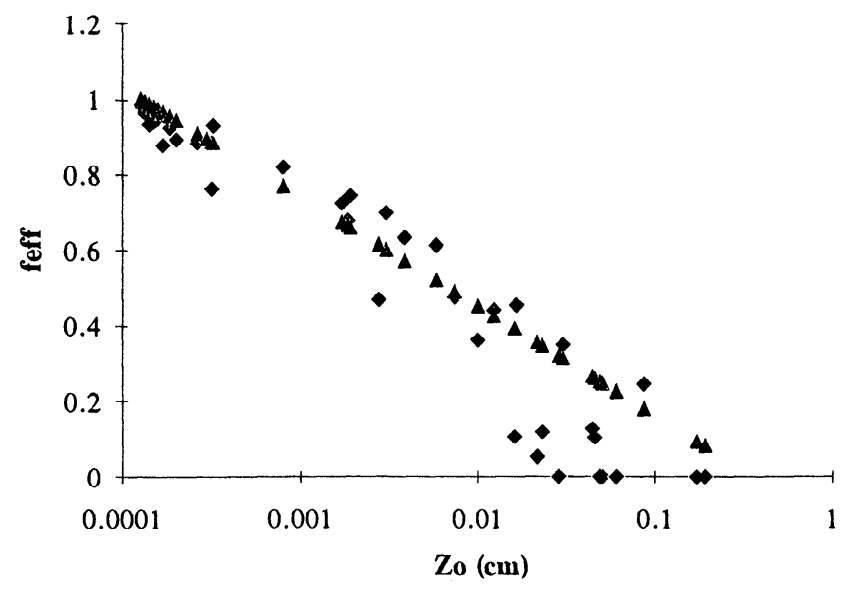

Figure 2. Efficient ratio $\mathrm{f}_{\text {eff }}=\mathrm{U}_{\mathrm{s}}^{*} / \mathrm{U}^{*}$ versus the roughness length $Z_{0}$; diamonds: Marshall's [1971] measurements; triangles, $\mathrm{f}_{\text {eff }}$ computed from equation (18). 
values shows that the proposed scheme gives a correct representation of the wind momentum partition between the surface and the erodible elements. However, the agreement is not very good for the highest values of the roughness height which correspond to high roughness densities. This approximately corresponds to the limit $\lambda=0.05$ indicated by Arya as a limit for the logarithmic wind profiles hypothesis to be applicable. However, these discrepancies correspond to efficient ratios lower than 0.15 , and beyond this value the relative error never exceeds $30 \%$. So the largest uncertainties will be generated in situations where erosion frequencies will be low. Finally, this confidence range is considered as really satisfying with regard to the limited number of parameters required by this partition scheme and the large-scale aims of this parameterization.

These results have also been compared to those obtained by matching Raupach's [1992] drag partition theory with Marshall's data (Figure 3). The latter have been computed as a function of $\lambda$ and using for $\beta$ and $\sigma$ the values indicated by Raupach (170 and 2, respectively). Both expressions generate similar errors in the same range of low efficient ratios; but finally, the confidence range of both drag partition schemes is roughly comparable.

By combining the size-dependent equation established in section 2.1 and the efficient ratio previously defined, an expression of the threshold friction velocity in a rough situation is obtained :

$$
\mathrm{U}_{\mathrm{t}}^{*}\left(\mathrm{D}_{\mathrm{p}} ; \mathrm{Z}_{0} ; \mathrm{z}_{0 \mathrm{~s}}\right)=\frac{\mathrm{U}_{\mathrm{ts}}^{*}\left(\mathrm{D}_{\mathrm{p}}\right)}{\mathrm{f}\left(\mathrm{Z}_{0}, \mathrm{z}_{0 \mathrm{~s}}\right)}
$$

\subsection{Erosion Fluxes}

2.3.1. Horizontal flux. Assuming that above the erosion threshold all the wind momentum is transferred to the surface by the saltating grains and based on dimensional arguments, Bagnold suggested that the

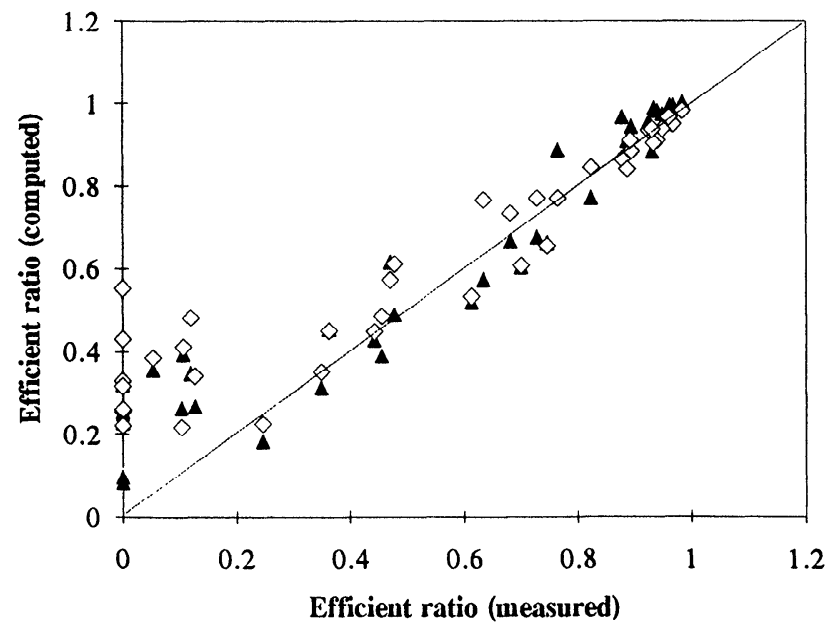

Figure 3. Predicted efficient ratios versus Marshall's [1971] measurements; diamonds: equation (10) [Raupach, 1992]; triangles, equation (18). horizontal flux is proportional to a power 3 of the wind friction velocity. Most of the expressions mentioned in the literature also exhibit a third power law of $U^{*}$ to express the horizontal flux. Such a dependence has been experimentally observed in natural situations or in windtunnel, especially for large values of $\mathrm{U}^{*}[$ Gillette, 1974, 1979; Gillette and Stockton, 1989; Sörensen, 1985; Leys and Raupach, 1991; Shao et al., 1993].

Greeley et al. [1994] have performed horizontal flux measurements using a trench at Pismo Beach (California), primarily to test the capabilities of various sand collectors. Because this experiment provides flux measurements with a high confidence level (5\% in mass), it also allows to test the reliability of the various equations proposed to retrieve the horizontal fluxes. These authors found that the Bagnold's [1941] model and White's [1979] formulation most closely agree with the experimental data. Thus and because only White's equation includes a threshold term, we retain this one as the expression in which the above parameterization of $\mathrm{U}_{\mathrm{t}}^{*}$ will be included.

As previously suggested by Kawamura [1951], White considered that the flux equation can be derived from an estimation of the characteristic pathlength of the saltating particles L:

$$
\mathrm{L} \approx \mathrm{W}^{2} / \mathrm{g}
$$

$\mathrm{W}$ is the mean vertical velocity of the saltating particles.

The total surface shear stress is assumed to be divided in two components:

$$
\tau_{0}-\tau_{\text {sand }}+\tau_{\text {wind }}
$$

To maintain the particles in motion, the wind shear stress must be $\tau_{\text {wind }}=\rho_{\mathrm{a}} \mathrm{U}_{\mathrm{t}}^{* 2} ; \tau_{\text {sand }}$ corresponds to the momentum transmitted by the impact of the particles colliding with the surface. It can be deduced

$$
\tau_{\text {sand }}=\rho_{a}\left(u^{* 2}-U_{t}^{* 2}\right)
$$

Above threshold it is also equal to the momentum loss:

$$
\tau_{\text {sand }}=\mathrm{M}\left(\mathrm{U}_{\mathrm{f}}-\mathrm{U}_{\mathrm{i}}\right)
$$

where $U_{f}$ is the mean final horizontal velocity of the saltating particles; $U_{i}$ is their mean initial horizontal velocity; and $M$ is the mass of material falling per unit area time. Assuming the collisions are inelastic, White deduced

$$
\mathrm{U}_{\mathrm{f}}-\mathrm{U}_{\mathrm{i}} \cong \mathrm{W}
$$

Accounting for the relation, experimentally observed, between the mass of particles in motion and the erosion threshold [White, 1979] 


$$
M \approx \rho_{a}\left(U^{*}-U_{t}^{*}\right)
$$

White derived an estimation of $\mathrm{W}$

$$
\mathrm{W} \approx \mathrm{U}^{*}+\mathrm{U}_{\mathrm{t}}^{*}
$$

leading to the following expression for the mean pathlength:

$$
\mathrm{L} \propto \frac{\left(\mathrm{U}^{*}+\mathrm{U}_{\mathrm{t}}^{*}\right)^{2}}{\mathrm{~g}}
$$

Since basically, the horizontal flux is assumed to be

$$
\mathrm{G} \approx \mathrm{ML}
$$

this leads to the following expression of the horizontal flux:

$$
\mathrm{G}=\mathrm{C} \frac{\rho_{\mathrm{a}}}{\mathrm{g}} \mathrm{U}^{* 3}\left(1+\frac{\mathrm{U}_{\mathrm{t}}^{*}}{\mathrm{U}^{*}}\right)\left(1-\frac{\mathrm{U}_{\mathrm{t}}^{* 2}}{\mathrm{U}^{* 2}}\right)
$$

C is a constant of proportionality with a value of 2.61 determined from wind tunnel experiments [White, 1979] this value being recently confirmed by the results of the Greeley et al. 's [1994] experiment.

Including, for an ideal case (i.e., all particles having the same diameter), the parameterization of the threshold friction velocity previously established in White's equation leads to express the horizontal flux as

$$
G\left(D_{p}\right)=E C \frac{\rho_{a}}{g} U^{*} 3(1+R)\left(1-R^{2}\right)
$$

where $\mathrm{R}=\frac{\mathrm{U}_{\mathrm{t}}^{*}\left(\mathrm{D}_{\mathrm{p}}, \mathrm{Z}_{0}, \mathrm{z}_{0 \mathrm{~s}}\right)}{\mathrm{U}^{*}}$ and $\mathrm{E}$ is the ratio of erodible to total surface.

The problem in applying this formulation to natural situations is that the soil grains are generally not characterized by a unique diameter. As the equation of the threshold friction velocity is not linearly dependent on the particle diameter, the adequate size-dependent threshold value will be affected to each size range, and thus the grain soil size distribution must be represented by a continuous function.

Lognormal functions have been chosen because they require a reasonable number of parameters, which is particularly convenient to describe multimodal distributions. Theses functions generally express the soil mass size distribution.

$$
\frac{d M\left(D_{p}\right)}{d \ln \left(D_{p}\right)}=\sum_{j=1}^{n} \frac{M_{j}}{\sqrt{2 \pi} \ln \left(\sigma_{j}\right)} \exp \left(\frac{\left(\ln D_{p}-\ln M M_{j}\right)^{2}}{-2 \ln ^{2} \sigma_{j}}\right)
$$

$D_{p}$ is particle diameter; $j$ refers to the $j$ th mode; $M_{j}$ is mass fraction of particles for mode $j ; M_{j}$ is mass median diameter of the $j$ th mode and $\sigma_{j}$ is geometric standard deviation.

The relative contribution to the total flux of each size range is assumed to be proportional to the relative surface it occupies on the total surface. The surface covered by each grain is assimilated to its basal surface. Thus a size distribution of the basal surfaces can be computed from the mass distribution, assuming spherical particles with the same density:

$$
d S\left(D_{p}\right)=\frac{d M\left(D_{p}\right)}{\frac{2}{3} \rho_{p} D_{p}}
$$

The total basal surface is

$$
S_{\text {total }}=\int_{D_{p}} d S\left(D_{p}\right) d D_{p}
$$

Dividing equations (30) by (31) gives a normalized continuous relative distribution of basal surfaces:

$$
\mathrm{dS}_{\mathrm{rel}}=\frac{\mathrm{dS}\left(\mathrm{D}_{\mathrm{p}}\right)}{\mathrm{S}_{\text {total }}}
$$

Finally, combining equations (28) and (32) allows to define an horizontal flux distribution as a function of the particle diameter:

$$
\mathrm{dG}\left(D_{\mathrm{p}}\right)=\mathrm{dS}_{\mathrm{rel}}\left(D_{\mathrm{p}}\right) \mathrm{G}\left(\mathrm{D}_{\mathrm{p}}\right)
$$

The total horizontal flux is computed by integrating the previous distribution on the studied range of particle diameters.

$$
G_{\text {tot }}=E C \frac{\rho_{a}}{g} U^{* 3} \int_{D_{p}}(1+R)\left(1-R^{2}\right) d S_{r e l}\left(D_{p}\right) d D_{p}
$$

This equation also allows to compute the contribution of each class of soil grains to the total horizontal flux.

2.3.2. Vertical flux. The dust flux, also called vertical flux, is composed by the finest particles setting in suspension from the saltation layer and is able to be longrange transported. It represents the mass of fine particles passing through a horizontal unit area per unit time. The suspension-saltation boundary is controlled by the ratio of the threshold friction velocity and the terminal velocity of the particles. The terminal velocity is defined by the equilibrium of the particle weight and the wind drag and so depends on the particle diameter and density. The value of the particle diameter for saltation-suspension boundary is about $50 \mu \mathrm{m}$ [Greeley and Iversen, 1985]. 
Moreover, particles with a diameter lower than this limit involve very high threshold friction velocities due to the strong cohesion forces linking them to each other (see Figure 1). Thus the movement of these fine particles is not initiated directly by the wind friction on the erodible surface and requires sandblasting or bombardment processes to disrupt the aggregates and produce dust particles that will be set in suspension [Gillette, 1979, 1981; Gomes et al., 1990; Shao et al., 1993]. Since dust production requires saltation as an intermediate process, the vertical flux is generally derived from the horizontal one.

Based on ratios of vertical to horizontal flux experimentally determined, Gillette and Passi [1988] have suggested to consider it as a linear function of the wind friction velocity:

$$
\mathrm{F} / \mathrm{G} \propto \mathrm{U}^{*}
$$

To investigate more thoroughly the relation between horizontal and vertical fluxes, Shao et al. [1993] have performed wind tunnel experiments of saltating sand grains on a loose dust bed. They have measured the total horizontal flux (sand plus dust) and determined by dry sieving the fraction of dust and sand to estimate the horizontal dust flux. To respect the mass conservation in the windtunnel, the authors assume that the vertical dust flux is equal to the horizontal dust flux divided by the length of the bed.

Their measurements show that both the total flux and the dust flux are proportional to a power 3 of the wind velocity. This result indicates that the ratio of vertical to horizontal flux does not depend on the wind friction velocity so that dust flux is a constant fraction of the total horizontal flux .

Shao et al. [1993] have also developed a theoretical analysis of the energetic of dust production. They consider that dust production corresponds to the rupturing of the interparticle bonds linking dust particles to the surface, by the impact of a saltating grain. They note $y$ the typical potential binding energy of the dust particles. The number $\mathbf{N}$ of dust particles ejected by impact is assumed to satisfy the condition

$$
N \psi=C_{N}\left(E_{f}-E_{i}\right)=C_{N} \frac{m_{S}}{2}\left(U_{f}^{2}-U_{i}^{2}\right)
$$

$\mathrm{C}_{\mathrm{N}}$ is a constant of proportionality which must be less than 1 .

$E_{f}=m_{s} U_{f}^{2} / 2$ is the kinetic energy of an impacting particle; $E_{i}=m_{s} U_{i}^{2} / 2$ is the kinetic energy of an ejected particle.

The dust flux is defined by

$$
F=m_{d} n N
$$

$m_{d}$ is the mass of a dust particle; $n$ is the number of saltation impacts per unit area and time; $n$ is deduced from the expression of the shear stress of the saltating particles:

$$
\tau_{p}=\rho_{a}\left(U^{* 2}-U_{t}^{* 2}\right)=n m_{s}\left(U_{f}-U_{i}\right)
$$

Shao et al. [1993] use a flux formulation based on an estimation of the typical pathlength of the saltating particles which differs from the one used in the White's formulation

$$
\mathrm{G}=\mathrm{C} \frac{\rho_{\mathrm{a}}}{\mathrm{g}} \mathrm{U}^{* 3}\left(1-\frac{\mathrm{U}_{\mathrm{t}}^{* 2}}{\mathrm{U}^{* 2}}\right)
$$

A relation between $F$ and $G$ is then established

$$
F=\frac{m_{d} g C_{N}}{\psi 2 c}\left(\frac{U_{f}+U_{i}}{U^{*}}\right) G=\alpha G
$$

An equivalent relation can be obtained using the White's hypothesis for the horizontal flux :

$\mathrm{n}$ is expressed as

$$
\mathrm{n}=\frac{\mathrm{G}}{\mathrm{m}_{\mathrm{s}} \mathrm{L}}
$$

as previously indicated, $L \approx W^{2} / g$ and $W \cong U_{f}-U_{i}$, so the relation between the vertical and the horizontal flux is

$$
F=\frac{m_{d} g C_{N}}{\psi c}\left(\frac{U_{f}+U_{i}}{U_{f}-U_{i}}\right) G=\alpha^{\prime} G
$$

Both $\alpha$ and $\alpha^{\prime}$ depend on $\psi$ and $C_{N}, \psi$ representing the resistance of the surface to be disrupted by the available energy characterized by $\mathrm{C}_{\mathrm{N}}$.

This proportionality relation between the vertical and the horizontal flux will be preferred to a linear relation with the wind friction velocity because of its experimental evidence, but mainly because it is sustained by physical bases. Considering the way $\alpha^{\prime}$ is defined, it is expected to vary with the nature of the eroded soil in relation with its capacity to provide fine particles.

This capacity is primarily controlled by the amount of available dust particles in the soil. Chemical analysis of desert aerosol samples have shown that these dust particles are mainly composed of aluminosilicated components [Glaccum and Prospero, 1980; Prospero et al. 1981], indicating that the soil fraction able to deliver fine particles is the clay fraction. When plotting, for Gillette's [1979] coupled measurements of horizontal and vertical flux, the mean ratio of these two fluxes against the clay content, for the soils having less than $20 \%$ clay, a clear trend is observed (Figure 4). Although the data are sparse, a linear fitting gives the following equation for $0 \%<(\%$ clay $)<20 \%$ :

$$
\log (F / G)=0.134 \text { (\%clay) }-6
$$




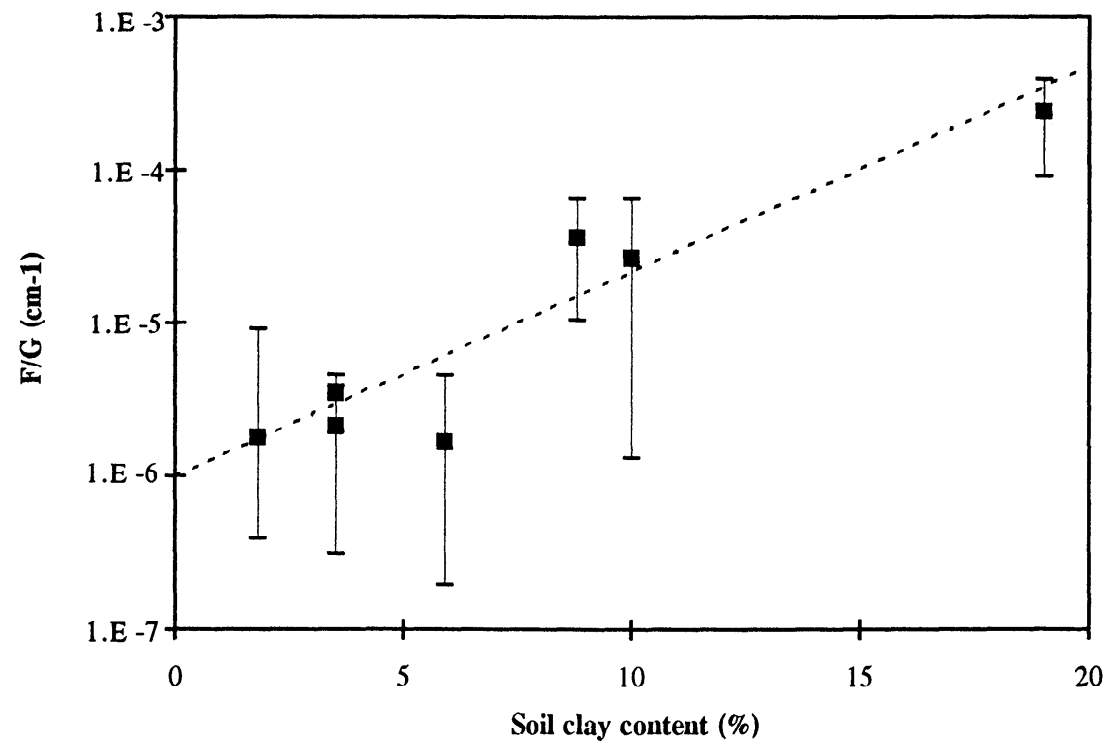

Figure 4. Ratio of vertical to horizontal flux $(F / G)$ for each soil type, versus the soil clay content [Gillette, 1979]; squares, averaged ratios (the uncertainties correspond to the extreme measured values); solid curve, linear regression (equation (43), $\mathrm{r}^{2}=0.93$ ).

Thus let us think that the ability of a soil to provide dust and thus the ratio of vertical to horizontal flux can be related, in first approximation, to its clay content. This relation does not appear to be relevant for soils having a clay content higher than $20 \%$. Indeed, one of the lowest mean ratios of vertical to horizontal flux in the Gillette's sample set is measured for a soil containing more than $50 \%$ of clay ("soil 9"). It is well known that soil exhibiting high clay content are crusted and highly resistant to wind erosion [Chepil, 1951; Gillette et al., 1982]. For these soils the dominant dust production process is not saltation but abrasion. According to the physical analysis proposed by Shao et al. [1993], the ratio a of vertical to horizontal flux depends on the resistance of the surface to be disrupted by the saltating particles and thus should be very different crusted and loose soils.

Considering the lack of physical description of the dust production due to wind erosion, it is not possible, at this time, to model more precisely the relation between the horizontal and the vertical fluxes. Consequently, the estimation of the ratio of vertical to horizontal fluxes will be based on equation (47).

\section{Validation}

\subsection{Conditions for Application}

3.1.1 Theoretical limitations. The theoretical basis, on which this dust production scheme is based, must be reexamined to clearly point out the existing hypothesis and then to precise its application range.
1. The parameterization of the threshold friction velocity versus the particle size is based on the Iversen and White [1982] expressions which result from the adjustment of semiempirical equations on experimental data. These data were obtained from wind-tunnel experiments with beds composed of particles having generally the same mean size. Thus using such a parameterization implies the assumption that the threshold friction velocity for a given particle size is not significantly modified when this particle is at rest on a bed composed of a mixing of erodible particles of various sizes.

2. The threshold friction velocities were determined for loose particles, thus the scheme is a priori applicable only to loose soils. In particular, it cannot be used for crusted soil, for which the cohesion of the soil grains is strong.

3. The flux formulations are generally used with a unique threshold friction velocity to characterize a given surface. In our scheme, a flux is computed for each size range, the total eroded flux being the sum of the specific size rates weighted by the relative surface of each size range. This provides the size distribution of the soil grains contributing to the total horizontal flux. Thus if the size distribution of the particles initially arisen is not significantly modified by the saltation process, for example by breakage of the soil aggregates, this distribution can be considered as an estimation of the sizedistribution of the saltating particles.

4. Given a soil size distribution and wind velocities, this model simulates horizontal and dust flux but does not account for the modification of the parent soil size distribution with time. Ignoring the kinetics of depletion of the soils implies that the stock of available particles is continuously supplied or that the soil mass eroded by the wind is negligible compared to the initial available mass 
and that the soil modification evolves sufficiently slowly to be neglected.

5. The way the dust flux is estimated from the horizontal flux does not explicitly account for the physical processes of dust production (especially the modifications of the size distribution occurring in the saltation layer). Thus the size distribution of the mineral aerosols produced by wind erosion cannot be deduced, at this time, directly from the parent soil size distribution.

6. The partition scheme is based on a theory established to describe the modifications of the wind profile following a step change in surface roughness, i.e., in a situation where two roughness lengths can be clearly affected by the surfaces before and after the roughness change. These results are extended to a situation where two roughness lengths are needed to characterize the various parts of the same surface (i.e., the overall surface and the erodible part of this surface). This can be done in situations where two logarithmic wind profiles coexist and thus implies a minimum spacing between the roughness elements. In this case, the partition scheme allows an estimation of the mean drag between two successive obstacles. Although this approach is a simplified representation of the physical processes involved in such complex situations, the agreement between those theoretical results and Marshall's measurements of drag partition indicates that this scheme gives a correct estimation of the mean partition, even for situation where the small-scale wind profile may not be logarithmic.

3.1.2. Determination of the required parameters. The dust flux computation requires as input parameters the size-distribution parameters of the erodible soil, the roughness length accounting for the roughness elements, and the roughness length of the erodible surface.

Soil size-distributions: Since we are interested in soil mobilization in natural conditions, the soil size distribution must be representative of the size distribution of the in-place soil aggregates. Thus they must be derived from methods disturbing as little as possible the real distribution. The soil size-distributions are generally determined by wet sedimentation methods, leading to the breakage of the soil aggregates and the release of the finest particles. Such estimations are not representative of the characteristics of the size distribution of the in-place soil particles. In particular, the very fine clayey particles are not significantly present in natural soils as loose individual particles. The soil size-distributions obtained by fitting lognormal functions on experimental data resulting from dry sieving of natural soil samples, for example those proposed by Chatenet et al. [in press], are more adapted to our purpose.

Overall roughness length, $\mathrm{z}_{0}$ : The drag coefficient and the roughness length are interchangeable descriptions of roughness, but the last one is considered height independent: for a homogeneous surface, wind profile measurements performed at any height in an inertial sublayer, whose structure is determined by the same homogeneous roughness, give a representative measurement of the roughness length. This roughness length is height independent but only in a sublayer defined by the surface scale on which the terrain can be considered homogeneous. In practice, this defines a minimum relevant fetch corresponding to the maximum measurement heights. Finally, a roughness length refers to a horizontal surface and its roughness characteristics. A similar problem has been investigated for large-scale modeling over heterogeneous surfaces since to compute the wind on a large scale, the cumulated effect of the various roughness characteristics must be accounted for. André and Blondin [1986] and Taylor [1987] agree that the integrative roughness length for a grid scale composed of various areas corresponding to different roughness lengths, is more influenced by the parts having the higher roughness lengths, so that the integrative value is higher than the surface averaged of the different roughness lengths. Wieringa [1993] also indicates that relatively rough patches contribute more to the effective roughness than their area fraction. Hence an integrative measurement of the roughness length can produce a high value for a surface spatially dominated by a lower roughness. Since wind erosion is a surface process, the model needs the roughness lengths reflecting the most frequent roughness state of the surface rather than the integrated effects of the cumulated roughness characteristics.

Smooth roughness length, $\mathrm{z}_{0 \mathrm{~s}}$ : Ideally, the smooth roughness length of the erodible surface could be measured on the site where the overall roughness length has been measured but without the nonerodible elements, as performed by Marshall [1971]. Since this cannot be done on natural sites, an alternative approach must be found.

A classical approach consists in characterizing the roughness length of an erodible surface in relation to the size of the erodible particles. A relation between the size of the particles composing a quiescent sand bed and its roughness length is generally admitted [Bagnold, 1941; Greeley and Iversen, 1985]:

$$
z_{0 s}=\frac{D_{p}}{30}
$$

For the typical size range of the erodible particles this relation leads to roughness lengths of the order of $10^{-4}$ to $10^{-3} \mathrm{~cm}$. Such values for smooth particles surface have been measured in a windtunnel [Gillette et al., 1982; $L i$ and Martz, 1994].

According to relation (45) the smooth roughness length is expected to vary from one soil to another in relation to their size distribution. Thus it is important to test the sensitivity of the partition scheme to this parameter and the precision required for its determination.

For different values of the overall roughness length, the efficient ratio $f_{\text {eff }}$ has been computed for smooth 
roughness lengths ranging from $210^{-4}$ to $310^{-3} \mathrm{~cm}$ (corresponding to particles diameters of 60 to $1000 \mu \mathrm{m}$ ). When using a mean value of $\mathrm{z}_{0 \mathrm{~s}}=10^{-3} \mathrm{~cm}$ to represent the whole range of smooth roughness lengths, the errors on $\mathrm{f}_{\text {eff }}$ exceed $40 \%$ only for the very low values of $z_{0 \text { s }}$ and they are lower than $20 \%$ for the major part of the considered range.

So that a value of the smooth roughness length $\mathrm{z}_{0 \mathrm{~s}}=10^{-3} \mathrm{~cm}$ can be considered as a correct estimation for most of the natural conditions, for which the smooth roughness length will be controlled by the size of the erodible particles.

\subsection{Validation of the Application of the Partition Scheme to Erosion}

The partition scheme, previously tested in ideal situations corresponding to Marshall's measurements, has been applied to retrieve experimental measurements of erosion threshold friction velocity for natural soils. Measurements of the threshold friction velocities were obtained by Gillette et al. [1982] and Nickling and Gillies [1989], by using portable wind tunnels, on various erodible sites of the United States. Since such measurements involve a small fetch and are thought to be representative of the eroded surface, the required conditions for the determination of the roughness lengths are assumed to be fulfilled.

The computations on the Gillette's data set have been performed only for the disturbed soils, for which the crust had been completely destroyed. The authors indicate that very low roughness lengths were measured for very smooth clay-crusted sites, these abnormal values have also been eliminated.

The aim of the Nickling and Gillies measurements was to measure vertical fluxes. To ensure a sufficient amount of erodible material, the tunnel was moved to a new location for each sample run. Thus the reported threshold friction velocities and roughness lengths are only averaged values for the various runs performed on each site. The measurements performed on sites where dust fluxes were measured for friction velocities lower than the threshold value have not been used.

For both experiments the roughness lengths were determined from wind velocity profiles. The threshold friction velocities have been measured at the moment where particles motion was first visible and thus will correspond to particle size for which the movement is most easily initiated. A reference value of the threshold friction velocity $\left(\mathrm{U}_{\mathrm{t}}^{*}\left(\mathrm{D}_{\mathrm{p}}\right) \approx 21.7 \mathrm{~cm} \mathrm{~s}^{-1}\right)$ is used to perform the computations; it corresponds to a range of a particle diameter of $120 \mu \mathrm{m}$, which is compatible with the available information on the grain size characteristics of the tested soils. The smooth roughness length used for the computation is $\mathrm{z}_{0 \mathrm{~s}}=10^{-3} \mathrm{~cm}$.
In Figure 5 the threshold friction velocities observed for various roughness lengths match the model prediction. The discrepancies with Gillette's measurements are generally lower than $30 \%$, with a better agreement in the range of 20 to $60 \mathrm{~cm} \mathrm{~s}^{-1}$. The latter friction velocities can be reached under reasonable wind conditions and thus correspond to situations where erosion can potentially frequently occur. The agreement with the values reported by Nickling and Gillies remains quite satisfying, although larger discrepancies, probably due to the averaging of measurements, are observed.

\subsection{Validation of the Parameterization of the Soil Size Distribution}

Even if the need to account for the size characteristics of the eroded soils is often mentioned [Nickling, 1988, 1994; Sörensen, 1985], the influence of a mixed soil size distribution on the eroded flux has been poorly investigated from both theoretical and experimental points of view.

Williams [1964] has performed wind tunnel measurements of the horizontal flux produced by several size distributions and various particle shapes, to test the influence of the nonsphericity of eroded particles on the erosion flux. In particular, the eroded fluxes and the corresponding size distributions were measured at different heights and various wind friction velocities for symmetrical, continuous, and truncated soil sizedistributions of sand particles. This data set allows the comparison of the computed and measured horizontal flux for the three soil size-distributions, but also the comparison of the simulated and observed size distributions of the eroded particles.

Since Williams characterized the soil size-distributions only by the mass fraction in five ranges of particle

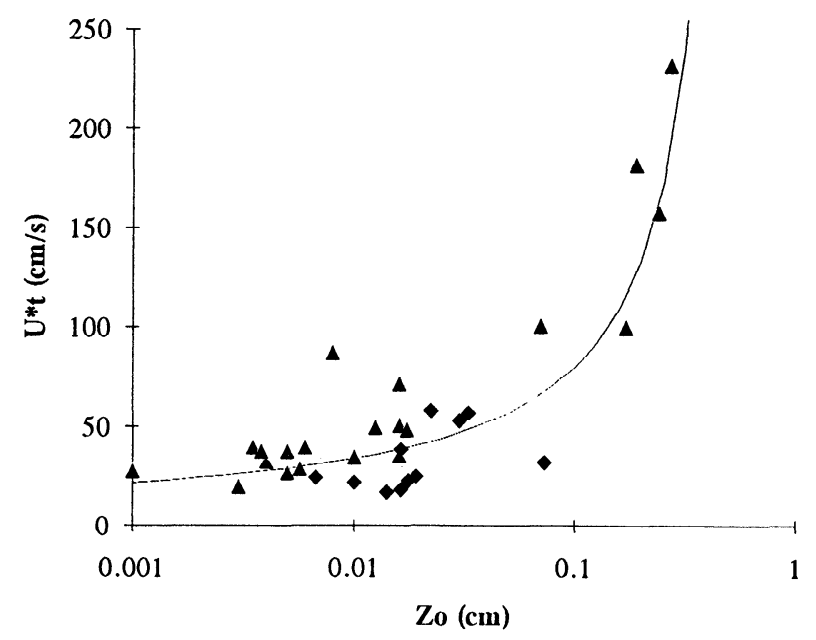

Figure 5. Threshold friction velocity $\left(U_{\mathfrak{t}}^{*}\right)$ versus roughness lengths $\left(Z_{0}\right)$; triangles, Gillette et al.[1982]; diamonds, Nickling and Gillies [1989]; solid curve, equation (20). 
diameter $(161,250,297,414$, and $550 \mu \mathrm{m})$, a reasonable adjustment of continuous functions on the experimental data was not possible. Thus to avoid a bias on the computed fluxes, the horizontal flux computation has been discretized and applied only to the indicated size ranges.

Firstly, a really good agreement is observed between the computed fluxes and the measured ones which cover 3 orders of magnitude (Figure 6), when using a unit value for the coefficient $\mathrm{C}$ in White's flux formulation. This result indicates that the soil size parameterization introduced in White's flux equation allows to retrieve the total eroded mass for both various soil size distributions and various wind friction velocities.

Secondly, the mass fractions of the various size ranges measured for the symmetrical distribution and the computed flux size-distribution can be compared to the initial soil size-distribution (Figure 7). The computed curves reproduce the general trend of the size distribution of the horizontal flux with the wind friction velocity: it is always finer than the parent soil, in particular the lowest wind friction velocity, but tends to the soil sizedistribution when the wind friction velocity increases. The eroded mass computed for each size range does not exactly match with the measured ones, in particular, the maximum of the computed curves is slightly finer, and the coarser fraction is generally underestimated. Nevertheless, the size classes used in William's experiment are too large to localize precisely the particle diameter corresponding to the maximum of the experimental size distributions. More informative, the cumulated fraction in the range of 250 to 297 is similar for all the computed and the measured flux size-distributions, indicating that the enrichment in finer particles of the horizontal flux is well reproduced by the model.

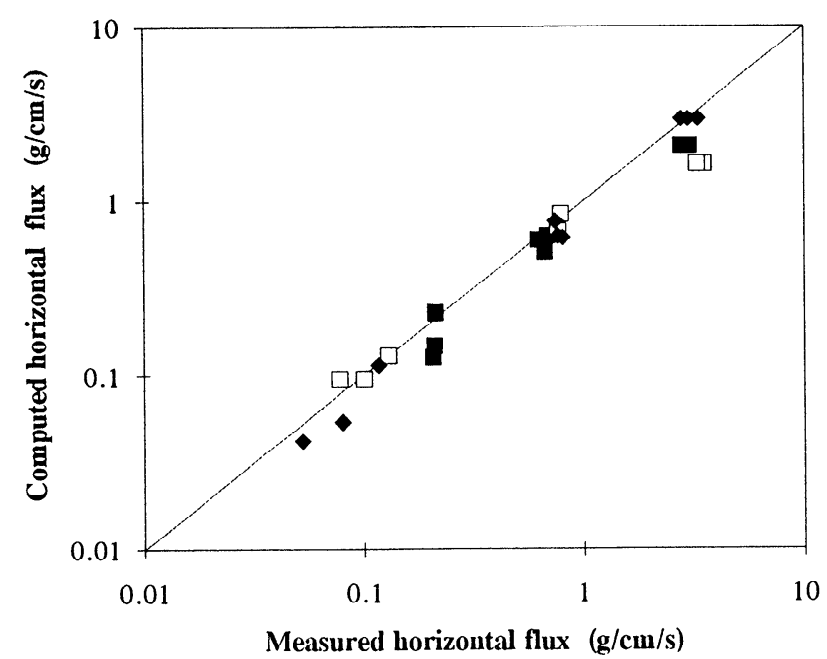

Figure 6. Predicted (equation (34), with $\mathrm{C}=1$ ) versus measured [Williams, 1964] horizontal fluxes; solid squares, symmetrical sand size distribution; open squares, truncated sand size distribution; diamonds, uniform sand size distribution.
To confirm these results, the same computation has been performed on the Aarhus windtunnel data reported by Sörensen [1985] for a wind friction velocity of $46 \mathrm{~cm} \mathrm{~s}^{-1}$. In this case, the agreement between the theoretical and the computed flux size distribution is really satisfying (Figure 8), the maxima of the two curves corresponding to the same particle diameter, both the increase of the fine particles and the decrease of the coarser ones being well reproduced.

\section{Concluding Remarks}

To improve the parameterization of desert dust sources for large-scale modeling issues, a physical model has been developed to quantify dust emissions in relation with the source characteristics. The model proposed here is based on a parameterization of the threshold wind friction velocity depending on the roughness of the surface, characterized by its roughness length and on the size distribution of the eroded soil. A specific production rate is affected to each soil size range by introducing a sizedependent threshold friction velocity in a horizontal flux formulation, weighted by the relative surface of the considered size range.

The reliability of the model has been evaluated at each step of its development by matching the simulations with relevant experimental data. The partition scheme used in this model, to account for the terrain roughness, is based on the roughness length of the rough surface and of the erodible one. Although potential theoretical limitations have been previously evoked (see section 3.1.1), it has been shown that this scheme allows to reproduce with a satisfying accuracy the erosion threshold measured in a wind tunnel for various natural sites covering a large range of threshold wind friction velocities. The size dependence of the horizontal flux with the size distribution of the parent soil appears to be physically relevant since it allows to retrieve not only the eroded mass but also the size distribution of the saltating particles measured during wind-tunnel experiments for various size distributions and wind friction velocities.

Finally, it is necessary to discuss the implications of the theoretical limitations of the model on its applicability for large-scale modeling, especially the following:

1. Some factors influencing erosion threshold such as moisture, salts, or organic matter content, are not explicitly parameterized. Although their effects are poorly documented, they mainly affect the soil cohesion [Nickling et Ecclestone, 1981; Gillette et al., 1982; Breuniger et al., 1989], and thus the size distribution of the in-place aggregates. Thus in the first approximation those effects are taken into account by the relation between the threshold wind friction velocity and the soil sizedistribution. Nevertheless, the relation between these factors and the soil size-distribution are not explicit, and thus their specific influence cannot be assessed. 

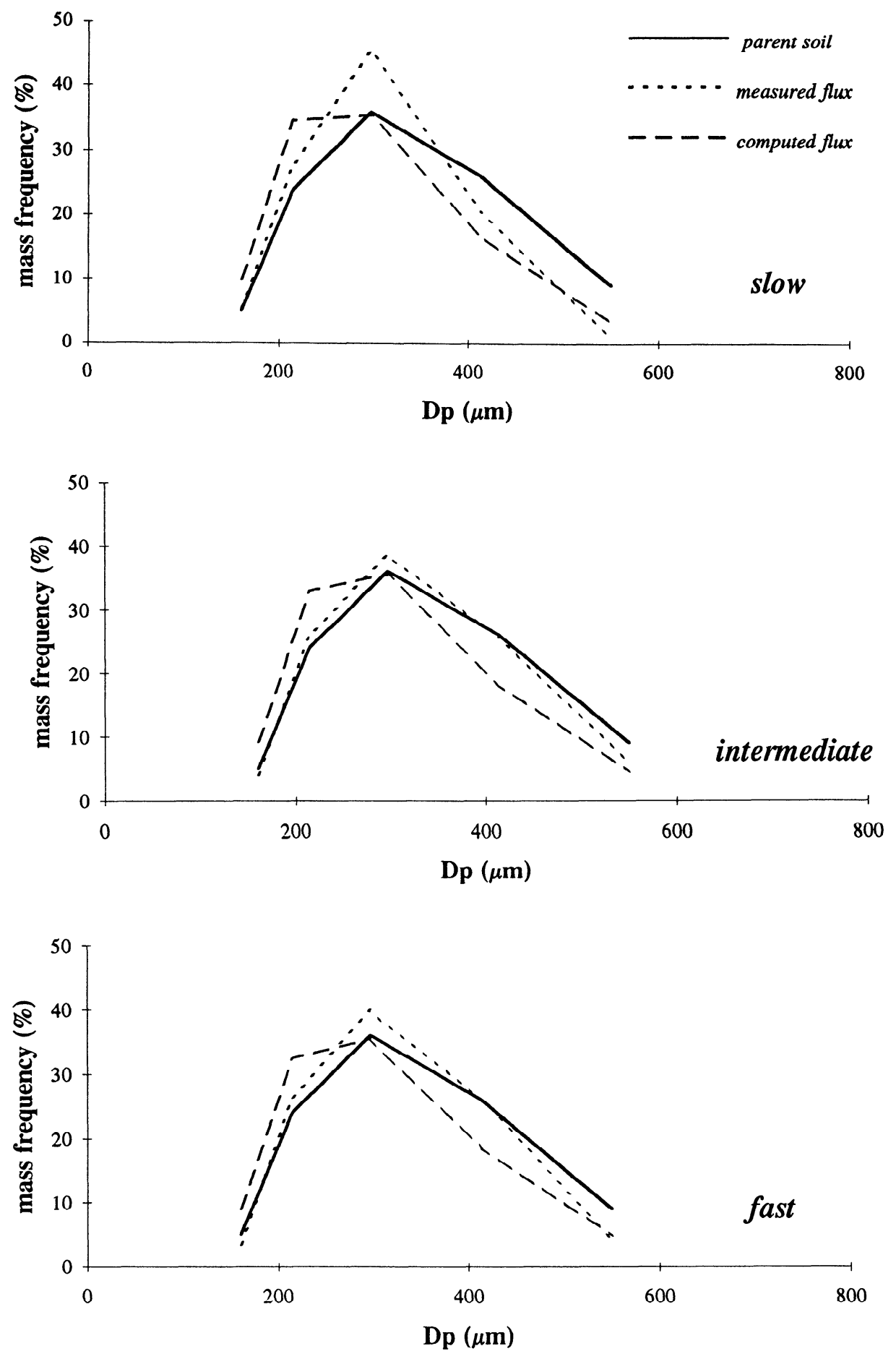

Figure 7. Measured [Williams, 1964] and predicted flux size distributions compared to the initial soil size distribution for three ranges of wind friction velocity (slow, $-50 \mathrm{~cm} \mathrm{~s}^{-1}$; intermediate, $\sim 70 \mathrm{~cm} \mathrm{~s}^{-1}$; fast, $\left.\sim 110 \mathrm{~cm} \mathrm{~s}^{-1}\right)$.

2. For a given surface the model provides a mass estimation of the emitted dust as a function of the wind friction velocity. The sources are thus considered as continuous, no parameterization of the soil evolution being performed. Indeed, the kinetics of the soil depletion is ignored in the present form of the model. Consequently, specific emissions from supply-limited sources cannot be correctly simulated. However, the climatic simulations generally involve time and space scales, for which soil modifications should not have a significant effect on the dust production. However, since the model required the parent soil size-distribution as an input parameter and 


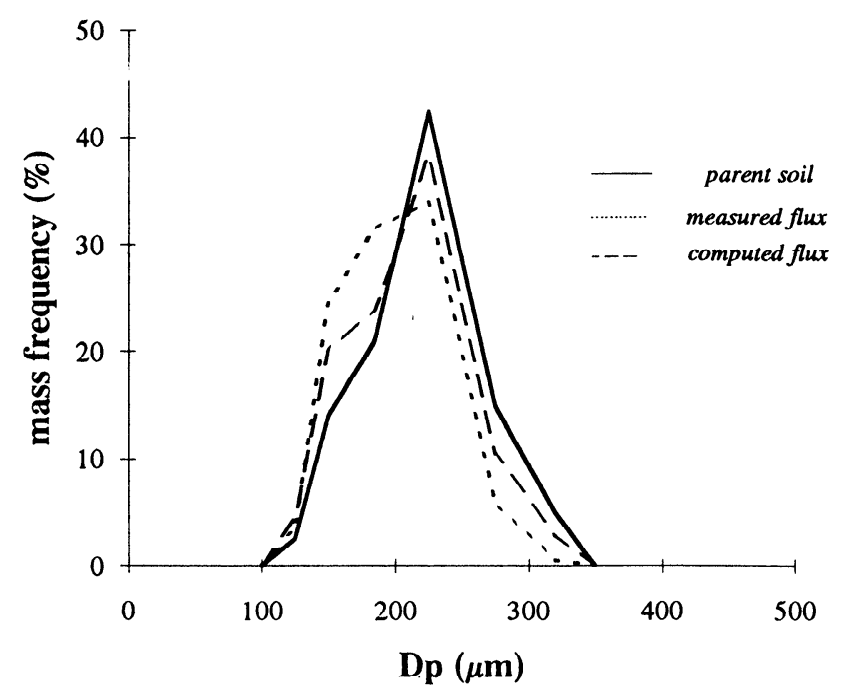

Figure 8. Measured [Sörensen, 1985] and predicted flux sizedistributions compared to the initial soil sizedistribution for a wind friction velocity of $46 \mathrm{~cm} \mathrm{~s}^{-1}$.

provides the amount of emitted dust, improving the model by adding a kinetic term will only imply a slight modification.

3. The model being applicable only to loose soils, the case of crusted soils can be approached in two ways: whether the crust, covering a loose soil, is thin enough to be rapidly disrupted, and thus applying the dust production scheme should only generate a slight overestimation on the erosion flux. Whether the crust is thick or resistant and the dust will be produced by abrasion, a process which has been poorly investigated. This process is generally considered as poorly efficient in term of soil mobilization, this assumption being supported by the high threshold friction velocities measured on crusted soils [Gillette, 1982]. For large-scale applications, until the physical processes of abrasion and crust disruption will be established, these areas will not be considered as dust sources.

4. The major weakness of this dust emission scheme concerns the estimation of the vertical flux, which is at this time considered a ratio of the horizontal flux depending on the soil clay content. Since it generates the most important uncertainties in the predicted dust fluxes and does not account for the physical processes really involved, this parameterization can only be viewed as a temporary solution, until these processes will be identified and quantified. Such an improvement should also allow to transfer the size distribution from the horizontal flux to the vertical dust flux. Indeed, this information is needed to correctly simulate dust transport and evaluate its potential climatic impact. The present dust flux estimation requires to assign a typical size distribution (such as those observed close to the source areas [D'Almeida, 1987; Shettle, 1984]) to the predicted dust flux.
Otherwise, a complete validation of the dust production model, coupling the partition scheme and the flux parameterization, was not possible, a complete data set of the required data is missing. Nevertheless, the independent validation of the various steps of the model constitutes strong constraints to confirm its physical bases.

To summarize, the dust production model proposed here provides an explicit parameterization of the dust amount produced by a given surface as a function of the wind friction velocity, in relation to the soil nature and its roughness. The input parameters are those able to be affected by climatic changes (modification of the soil nature, of the vegetation cover, etc.). Moreover, the model is thought to be simple enough to be coupled with an atmospheric transport model.

A large-scale application has been performed on a selected area of the Saharan Desert by simulating typical dust events and monthly averaged frequencies of dust events. The comparison of these simulations with atmospheric dust loads derived from satellite measurements allows to evaluate the applicability of this scheme at scales adapted to the grid of atmospheric transport models [Marticorena et al., manuscript in preparation, 1995]

Acknowledgments. We are grateful to S. Alfaro and L. Gomes for fruitful discussions during the development of this work. We want also to thank D.A. Gillette, J.A. Iversen, and W.G. Nickling for useful advice and D.A. Gillette, and W.G. Nickling for providing their experimental data set. This work has been supported by the "Programme Environnement du CNRS" in the framework of the action "Erosion Eolienne en Régions Arides et Semi-arides."

\section{References}

André, J.C., and C. Blondin, On the effective roughness length for use in numerical three-dimensional models, Boundary Layer Meteorol.,35, 231-245, 1986.

Arya, S.P.S., A drag partition theory for determining the large-scale roughness parameter and wind stress on Arctic pack ice, J. Geophys. Res., $80,3447-3454,1975$

Arya, S.P.S., and M.S. Shipman, An experimental investigation of flow and diffusion in the disturbed boundary layer over a ridge, I, Mean flow and turbulence structure, Atmos. Environ., 15, 1173-1184, 1981.

Bagnold, R.A., The Physics of Blown Sand and Desert Dunes, 265 pp., Methuen, New York, 1941

Breuninger, R. H., D.A. Gillette, and R. Khil, Formation of winderodible aggregates for salty soils and soils with less than $50 \%$ sand composition in natural terrestrial environments, in Paleoclimatology and Paleometeorology: Modern and Past Patterns of Global Atmospheric Transport, edited by M. Leinen and M. Sarthein, pp. 31-63, Kluwer Academic, Norwell, Mass., 1989.

Chatenet, B., B. Marticorena, L. Gomes, and G. Bergametti, Assessing the grain-size distri-bution of desert soils erodible by wind, Sedimentology, in press, 1995.

Chepil, W.S., Dynamics of wind erosion. SoilSci., 60, 305-320; 397-411; 475-480, 1945.

Chepil, W.S., Propertics of soil which influence wind erosion, 4, State of dry aggregate structure, Soil Sci., 72, 387-401, 1951. 
D'Almeida, G. A., On the variability of acrosol radiative characteristics, J. Geophys. Res., 92,3017-3026, 1987.

De Angelis, M., N.I. Barkov, and V.N. Petrov, Aerosols concentıations over the last climatic cycle $(160 \mathrm{Ky})$ from an antarctic ice core, Nature, 325, 318-321, 1987.

Elliot, W.P., The growh of the atmospheric internal boundary layer, Eos Trans. $A G U, 39,1048-1054,1958$.

Gaudichet, A., M. De Angelis, S. Jousseaume, J.R. Petit, Y. Korotkevitch, and V.N. Petrov, Comments on the origin of dust in Antarctica for present and ice age conditions, J. Atmos. Chem., 14, 129-142, 1992.

Genthon, C., Simulations of desert dust and sea salt aerosols in Antarctica with a general circulation model of the atmosphere, Tellus, 44(B) 371-389, 1992.

Gillette, D.A., On the production of soil wind erosion aerosols having the potential for long range transport, J. Rech. Atmos., 8, 735-744, 1974.

Gillette, D.A., Environmental factors affecting dust emission by wind erosion, in Saharan Dust, edited by C. Morales, pp. 71-94, John Wiley, New York, 1979.

Gillette, D.A., Production of dust that may be carried great distances, in Desert Dust : Origin, Characteristics and Effect on Man, Spec. Pap. Geol. Soc. Am. 186, 11-26, 1981.

Gillette, D.A., and R. Passi, Modeling dust emission caused by wind erosion, J. Geophys. Res., 93, 14,233-14,242, 1988.

Gillette, D.A., and P. H. Stockton, The effect of nonerodible particles on wind erosion of erodible surfaces, J. Geophys. Res., 94, 12,885-12,893, 1989.

Gillette, D.A., J. Adams, D.R. Muhs, and R. Khil, Threshold friction velocities and rupture moduli for crusted desert soils for the input of soil particles into the air, J. Geophys. Res., 87, 9003-9015, 1982.

Glaccum, R. A., and J. M. Prospero, Saharan aerosols over the Tropical North Atlantic-Mineralogy, Mar. Geol., 37, 295-321, 1980.

Glaser, A. H., The temperature above an airport runway on a hot day: Moist climate, Texas A \& M Research Foundation contract AF 19(604)977, Sci. Rep. 5, 11 pp., 1955.

Gomes L., G. Bergametti, G. Coudé-Gaussen, and P. Rognon, Submicron desert dust: A sandblasting process, J. Geophys. Res., 95, $13,927-13,935,1990$.

Greeley, R., and J.D. Iversen, Wind as a Geological Process on Earth, Mars, Venus and Titan, 333 pp., Cambridge University Press, New York, 1985.

Greeley, R., D.G. Blumberg, and S.H. Williams, Field measurements of active windblown sand, in Abstract of the Workshop on Response of Eolian Processes to Global Change, editcd by the Descrt Rescarch Institute, Occas. Pap. 2, Reno, Nev., 1994.

Grousset, F., P.E. Biscaye, M. Revel, J.R. Petit, K. Pye, S. Jousseaume, and J. Jouzel, Antarctic (Dome C) ice-core dust at $18 \mathrm{Ky}$ B.P.: Isotopic constraints on origins, Earth Planet. Sci. Lett., 111, 175-182, 1992.

Iversen, J.D., and B.R. White, Saltation threshold on Earth, Mars and Venus, Sedimentology, 29, 111-119, 1982.

Iversen, J.D., J.B. Pollack, R. Greeley, and B.R. White, Saltation threshold on Mars: The effect on interparticle force, surface roughness, and low atmospheric density, Icarus, 29, 381-393, 1976.

Jousseaume, S., Three-dimensional simulations of the atmospheric cycle of desert dust particles using a general circulation model, J. Geophys., Res., 95, 1909-1941, 1990.

Jousseaume, S., Paleoclimatic tracers: An investigation using an atmospheric general circulation model under ice age conditions, 1. Desert dust, J. Geophys. Res., 98, 2767- 2805, 1993.

Kawamura, R., Study on sand movement by wind, Inst. of Sci. and Technol., Rep. 5, 95-112, Tokyo, 1951.

Leys, J.F., and M.R. Raupach, Soil flux measurements with a portable wind erosion tunnel, Aust. J. Soil Res., 29, 533-552, 1991.

Li, L., and L.W. Martz, Systems of numeric models for sand particle transport by wind, J. Geophys. Res., 99, 12,999-13,012, 1994.

Marshall, J.K., Drag measurements in roughness arrays of varying density and distribution, Agric. Meteorol., 8, 269-292, 1971.

Musick, H.B., and D.A. Gillette, Field evaluation of relationships between a vegetation structural parameter and sheltering against wind erosion, Land Degradation Rehabil., 2, 87-94, 1990.

Nickling, W.G., The initiation of particle movement by wind, Sedimentology, 31, 111-117, 1988.
Nickling, W.G., Aelioan sediment transport and deposition, in Sediment Transport and Depositional Processes, edited by K. Pye, pp. 293-350, Blackwell Scientific, Boston, Mass., 1994.

Nickling, W.G., and M. Ecclestone, The effects of soluble salts on the threshold shear velocity of fine sand, Sedimentology, 28, 505-510, 1981.

Nickling, W.G., and J.A. Gillies, Emission of fine-grained particulates from desert soils, in Paleoclimatology and Paleometeorology: Modern and Past Palterns of Global Atmospheric Transport, edited by M. Leinen and M. Sarnthein, pp. 133-165, Kluwer Academic, Norwell, Mass., 1989.

O'Loughlin, E.M., and V.S.S. Annambhotla, Flow phenomena near rough boundaries, J. Hydraul. Res., 7, 231-250, 1969.

Pendergrass, W., and S.P.S . Arya, Dispersion in neutral boundary layer over a step change in surface roughness, I, Mean flow and turbulence structure, Atmos. Environ., 18, 1267-1279, 1984.

Petit, J.R., M. Briat, and A. Royer, Ice age aerosol content from Antarctic ice core samples ar. past wind strength, Nature, 293, 391-394, 1981.

Priesley, C.H.B., Turbulent Transfer in the Lower Atmosphere, 130 pp., University of Chicago Press, Chicago, Ill., 1959.

Prospero, J.M., and R.T. Nees, Dust concentration in the atmosphere of the Equatorial North Atlantic: possible relation- ship to the Sahelian drought, Science, 196, 1196-1198, 1977.

Prospero J. M. R. A. Glaccum. and R. T. Nees, Atmospheric transport of soil dust from Africa to South America, Nature, 289, 570-572, 1981.

Raupach, M.R., Drag and drag partition on rough surfaces, Boundary Layer Meteorol., 60, 375-395, 1992.

Raupach, M.R., D.A. Gillette, and J.F. Leys, The effect of roughness elements on wind erosion threshold, J. Geophys. Res., 98, 3023-3029, 1993.

Schlichting, H., Experimentelle Untersuchungen zum Rauhigkeitsproblem, Ingr. Arch., 7, 1-34, 1936. (English Translalation; NASA Tech. Memo. 823, 1936).

Shao, Y., M.R. Raupach, and P.A. Findlater, Effect of saltation bombardment on the entrainment of dust by wind, J. Geophys. Res., 98, 12,719-12,726, 1993.

Shettle, E. P., Optical and radiative properties of a desert aerosol model, in Proceedings of the Symposiunm on Radiation in the Atmosphere, edited by G. Fiocco, pp 74-77, A. Deepak, Hampton, Va., 1984.

Sörensen, M., Estimation of some aeolian saltation transport parameters from transport rate profiles, in Proceedings of the Intemational Workshop on the Physics of Blown Sand, edited by O.E. Barndorff- Nielsen, J.T. Möller, K. Römer Rasmussen, and B.B. Willets, pp. 141-190, University of Aarhus, Aarhus, Denmark, 1985.

Taylor, P. A., Comments and further analysis on the effective roughness length for use in numerical three-dimensional models, Boundary Layer Meteorol.,39, 403-419,1987.

Thompson, L.G., Variations in microparticle concentration, size distribution and elemental composition found in Camp Century, Greenland, and Byrd station, Antarctica, deep ice cores, in Isotopes and Impurities in Snow and Ice, LAHS, 118, 351-364, 1977.

Wieringa, J, Representative roughness parameters for homogeneous terrains, Boundary Iayer Meteorol., 63, 323-363, 1993.

Williams, G., Some aspect of the acolian saltation load, Sedimentology, 3. 253-256, 1964.

White, B.R., Soil transport by winds on Mars, J. Geophys. Res., 84, 4643-4651, 1979.

Wolfe, S.A., and W.G. Nickling, Shear stress partitioning in sparsely vegetated desert canopies, in Abstract of the Workshop on Response of Eolian Processes to Global Change, edited by the Desert Research Institute, Occas. Pap. 2, Reno, Nev., 1994.

G. Bergametti and B. Marticorena Laboratoire Interuniversitaire des Systèmes Atmosphériques, URA CNRS 1404, Université Paris VII et XII, Centre Multidisciplinaire de Créteil, 61 avenue du Général de Gaulle, 94010 Créteil cedex, France. (e-mail: bergametti@univ-paris12.fr)

(Received October 4, 1994; revised February 21, 1995; accepted February 21, 1995) 